\title{
Analisis Distribusi Gamma Bivariat
}

\author{
Jadid Irtakhoiri $^{1, \text { a) }}$, Suyono ${ }^{2, \text { b) }}$, Vera Maya Santi ${ }^{2, c)}$ \\ ${ }^{1}$ Program Studi Matematika, Fakultas Matematika dan Ilmu Pengetahuan Alam, Universitas Negeri Jakarta \\ ${ }^{2}$ Program Studi Statistika, Fakultas Matematika dan Ilmu Pengetahuan Alam, Universitas Negeri Jakarta \\ Email: a) jadidirtakhoiri22@gmail.com, ${ }^{\text {b) }}$ synjkt@yahoo.com, ${ }^{c)}$ vera.indr4@gmail.com
}

\begin{abstract}
This thesis discusses about Gamma bivariate distribution especially construction and characteristic of Gamma bivariate distribution. Construction is based on the characteristics of Gamma and Beta distribution, and also build joint p.d.f and conditional p.d.f. Gamma bivariate distribution was formed by defining $X=U W$ and $Y=V W$, which is $U$ and $V$ are Gamma distribution and $W$ is Beta distribution. Construction solved using the Whittaker function to help the process of integration in forming joint p.d.f Gamma bivariate distribution. Characteristics of Gamma bivariate distribution discussed in this thesis are about product moment, covariance, and correlation.
\end{abstract}

Keywords: Gamma distribution, Beta distribution, Gamma bivariate distribution, Whittaker function, correlation, covariant, joint p.d.f.

\begin{abstract}
Abstrak
Skripsi ini membahas mengenai distribusi Gamma bivariat khususnya tentang konstruksi dan karakteristik dari distribusi Gamma bivariat. Gamma bivariat dikonstruksi berdasarkan karakteristik dari distribusi Gamma dan distribusi Beta, serta membangun p.d.f bersama, dan p.d.f bersyarat. Gamma bivariat dibentuk dengan mendefinisikan variabel acak $\mathrm{X}=\mathrm{UW}$ dan $\mathrm{Y}=\mathrm{VW}$, dimana $\mathrm{U}$ dan $\mathrm{V}$ berdistribusi Gamma dan W berdistribusi Beta. Konstruksi dilakukan dengan memanfaatkan fungsi Whittaker untuk membantu proses pengintegralan dalam membentuk p.d.f bersama distribusi Gamma bivariat. Karakteristik distribusi Gamma bivariat yang dibahas adalah product moment, kovariansi, dan korelasi.
\end{abstract}

Kata-kata kunci: Distribusi Gamma, distribusi Beta, distribusi Gamma bivariat, fungsi Whittaker, korelasi, kovariansi, p.d.f bersama.

\section{PENDAHULUAN}

Situasi atau kejadian yang terjadi pada kehidupan sehari-hari seringkali tidak dapat diprediksi secara pasti. Sebagai contoh, lama waktu pelayanan seseorang di bank, lama waktu rusaknya suku cadang dan alat listrik, lama waktu suatu wilayah mengalami kekeringan juga tidak dapat diprediksi dan lain-lain. Lama waktu tersebut dapat dimodelkan dengan variabel acak nonnegatif. Karena waktu kejadiannya kontinu, maka model yang sesuai adalah variabel acak kontinu.

Pada pemodelan lama waktu perlu dipelajari distribusi dari variabel acak kontinu nonnegatif. Salah satu distribusi yang dapat digunakan untuk pemodelan lama waktu adalah distribusi Gamma. Jika hanya satu variabel acak yang menjadi perhatian maka dapat digunakan distribusi Gamma univariat. Sebagai contoh, lama waktu bola lampu dapat menyala dari pertama kali pembelian. Variabel lama waktu tersebut merupakan variabel acak kontinu nonnegatif. Salah satu distribusi yang dapat digunakan untuk memodelkan situasi tersebut adalah distribusi Gamma univariat.

Kenyataannya dalam suatu situasi yang terjadi pada kehidupan sehari-hari sering diperlukan dua variabel acak sekaligus. Sebagai contoh, dalam bidang hidrologi tingkat besarnya keparahan 
kekeringan suatu wilayah tidak dapat diprediksi secara langsung, namun diperlukan besarnya intensitas keparahan kekeringan dan lama waktu kekeringan itu sendiri. Keduanya merupakan variabel acak kontinu nonnegatif. Salah satu distribusi yang dapat digunakan untuk memodelkan situasi tersebut adalah distribusi Gamma bivariat.

Banyak peneliti yang telah melakukan kajian terhadap distribusi Gamma bivariat. Distribusi Gamma bivariat memiliki banyak fungsi kepadatan peluang (Samuel \& Balakrishnan, 2000). Fungsi kepadatan peluang distribusi Gamma bivariat dapat dikonstruksi oleh variabel acak dari satu keluarga yaitu keluarga distribusi Eksponensial (Nadrajah, 2005). Tidak seperti distribusi normal, distribusi Gamma tidak memiliki perluasan yang unik untuk bivariat atau multivariat (Kim, 2017). Distribusi ini memiliki bentuk kurva frekuensinya yaitu bell type, two tailed curve yang biasanya tidak simetris (Markovic, 1965). Pada skripsi ini akan dibahas konstruksi distribusi Gamma bivariat serta dianalisis sifat-sifat dari distribusi Gamma bivariat.

\section{METODE}

\section{Variabel Acak}

Suatu variabel acak yang dinotasikan $\mathrm{X}$ adalah suatu fungsi yang didefinisikan pada ruang sampel $S$ yaitu $S=e_{1}, e_{2}, \ldots, e_{n}$ sehingga menghasilkan nilai $X(e)=x$, dengan $e \epsilon S$ dan $x \in R$.

Jika himpunan semua hasil yang mungkin dari variabel acak berhingga atau tak berhingga tetapi masih dapat dihitung maka disebut sebagai variabel acak diskrit. Jika semua hasil yang mungkin dari variabel acak merupakan nilai dalam suatu interval maka disebut sebagai variabel random kontinu (Bain dan Engelhardt, 1991).

Variabel acak $\mathrm{X}$ merupakan variabel acak kontinu jika terdapat fungsi nonnegatif $\mathrm{f}$ sedemikian hingga c.d.f dari $\mathrm{x}, \mathrm{F}(\mathrm{x})$ dapat dinyatakan sebagai

$$
\mathrm{F}(\mathrm{x})=\int_{-\infty}^{x} f(t) d t
$$

Misalkan X merupakan suatu variabel acak kontinu yang mempunyai p.d.f $\mathrm{f}(\mathrm{x})$ ekspektasi dari $\mathrm{X}$ adalah

$$
\mathrm{E}(\mathrm{X})=\int_{-\infty}^{x} x f(x) d x
$$

Ekspektasi dari variabel acak $\mathrm{X}$ memenuhi sifat

1. $\mathrm{E}(\mathrm{k})=\mathrm{k}$. k merupakan konstanta

2. $\mathrm{E}[\mathrm{ku}(\mathrm{X})]=\mathrm{kE}[\mathrm{u}(\mathrm{X})]$

3. $\mathrm{E}\left(\mathrm{k}_{1} \mathrm{X}_{1}+\mathrm{k}_{2} \mathrm{X}_{2}\right)=\mathrm{k}_{1} \mathrm{E}\left(\mathrm{X}_{1}\right)+\mathrm{k}_{2} \mathrm{E}\left(\mathrm{X}_{2}\right)$

Misalkan $\mathrm{X}$ variabel acak kontinu dengan p.d.f $\mathrm{f}(\mathrm{x})$ dan ekspektasi $\mu$. Variansi dari $\mathrm{X}$ adalah sebagai berikut

$$
\operatorname{Var}(\mathrm{X})=\sigma^{2}=\mathrm{E}\left(\mathrm{X}^{2}\right)-\mu^{2}
$$

\section{Distribusi Bersama dari Dua Variabel Acak Kontinu}

Variabel acak $X_{1}$ dan $X_{2}$ merupakan variabel acak kontinu jika terdapat fungsi nonnegatif $f\left(x_{1}, x_{2}\right)$ sedemikian hingga c.d.f bersama $\mathrm{F}\left(\mathrm{x}_{1}, \mathrm{x}_{2}\right)$ dapat dinyatakan sebagai

$$
\mathrm{F}\left(\mathrm{x}_{1}, \mathrm{x}_{2}\right)=\int_{-\infty}^{x_{2}} \int_{-\infty}^{x_{1}} f(u, v) d u d v
$$
sifat

Fungsi $f\left(x_{1}, x_{2}\right)$ dinamakan p.d.f bersama dari variabel acak $X_{1}$ dan $X_{2}$. Fungsi $f\left(x_{1}, x_{2}\right)$ mempunyai

$$
\begin{aligned}
& \int_{-\infty}^{\infty} \int_{-\infty}^{\infty} f\left(x_{1}, x_{2}\right) d x_{1} d x_{2}=1 \\
& \mathrm{f}\left(\mathrm{x}_{1}, \mathrm{x}_{2}\right) \geq 0, \mathrm{x}_{1}, \mathrm{x}_{2} \in \mathrm{R}
\end{aligned}
$$

\section{Fungsi P.d.f Marginal dan Besyarat}

Misalkan $F\left(x_{1}, x_{2}\right)$ adalah c.d.f dari variabel acak kontinu $X_{1}$ dan $X_{2}$ dan $f\left(x_{1}, x_{2}\right)$ adalah p.d.f bersama dari $\mathrm{X}_{1}$ dan $\mathrm{X}_{2}$. Fungsi p.d.f marginal dari $\mathrm{X}_{1}$ adalah 


$$
\mathrm{f}_{1}\left(x_{1}\right)=\int_{-\infty}^{\infty} f\left(x_{1}, x_{2}\right) d x_{2}
$$

dan fungsi p.d.f marginal dari $\mathrm{X}_{2}$ adalah

$$
\mathrm{f}_{2}\left(x_{2}\right)=\int_{-\infty}^{\infty} f\left(x_{1}, x_{2}\right) d x_{1} \text {. }
$$

Fungsi kepadatan peluang bersyarat dari variabel acak kontinu $\mathrm{X}_{2}$ jika diberikan $\mathrm{X}_{1}=x_{1}$ adalah

$$
\mathrm{f}\left(x_{2} \mid x_{1}\right)=\frac{f\left(x_{1}, x_{2}\right)}{\mathrm{f} 1\left(x_{1}\right)} \text { untuk } \mathrm{f}_{1}\left(x_{1}\right)>0
$$

\section{Kovariansi dan Korelasi}

Misalkan $\mathrm{X}_{1}$ dan $\mathrm{X}_{2}$ adalah variabel acak yang mempunyai p.d.f bersama $\mathrm{f}\left(\mathrm{x}_{1}, \mathrm{X}_{2}\right)$. Kovariansi dari variabel acak $\mathrm{X}_{1}$ dan $\mathrm{X}_{2}$ adalah

$\operatorname{Cov}\left(\mathrm{X}_{1}, \mathrm{X}_{2}\right)=\mathrm{E}\left[\left(\mathrm{X}_{1}-\mu_{1}\right)\left(\mathrm{X}_{2}-\mu_{2}\right)\right]$

dan korelasi dari variabel acak $\mathrm{X}_{1}$ dan $\mathrm{X}_{2}$ adalah

$$
\operatorname{Corr}\left(\mathrm{X}_{1}, \mathrm{X}_{2}\right)=\frac{\operatorname{Cov}\left(\mathrm{X}_{1}, \mathrm{X}_{2}\right)}{\sqrt{\operatorname{Var}\left(X_{1}\right) \operatorname{Var}\left(X_{2}\right)}}
$$

\section{Independensi}

Misalkan $X_{1}$ dan $X_{2}$ merupakan variabel acak yang memeiliki p.d.f bersama $f\left(x_{1}, x_{2}\right)$ dan p.d.f marginal $\mathrm{f}_{1}\left(\mathrm{x}_{1}\right)$ dan $\mathrm{f}_{2}\left(\mathrm{x}_{2}\right)$. Variabel-variabel acak $\mathrm{X}_{1}$ dan $\mathrm{X}_{2}$ dikatakan saling bebas (independen) jika dan hanya jika

$$
\mathrm{f}\left(\mathrm{x}_{1}, \mathrm{x}_{2}\right) \equiv \mathrm{f}_{1}\left(\mathrm{x}_{1}\right) \mathrm{f}_{2}\left(\mathrm{x}_{2}\right)
$$

Variabel acak yang tidak independen dikatakan saling bergantung (dependen).

Misalkan variabel acak $X_{1}$ dan $X_{2}$ memiliki p.d.f bersama $f\left(x_{1}, X_{2}\right)$. Variabel-variabel $X_{1}$ dan $X_{2}$ dikatakan saling bebas (independen) jika dan hanya jika $\mathrm{f}\left(\mathrm{x}_{1}, \mathrm{x}_{2}\right) \equiv \mathrm{g}\left(\mathrm{x}_{1}\right) \mathrm{h}\left(\mathrm{x}_{2}\right)$ dimana $\mathrm{g}\left(\mathrm{x}_{1}\right)$ merupakan fungsi dari $\mathrm{x}_{1}$ dan $\mathrm{h}\left(\mathrm{x}_{2}\right)$ fungsi dari $\mathrm{x}_{2}$ saja.

\section{Fungsi Confluent Hypergeometric}

Fungsi Whittaker $\mathrm{W}(\lambda, \eta)$ didefinisikan sebagai

$$
\mathrm{W}_{\lambda, \eta}(\mathrm{z})=\mathrm{z}^{\eta+1 / 2} \exp (-\mathrm{z} / 2) / \Gamma(\eta-\lambda+1 / 2) \int_{0}^{\infty} \exp (-z t) t^{\eta-\lambda-1 / 2}(1+t)^{\eta+\lambda-1 / 2} d t
$$

$\operatorname{dimana}(\eta-\lambda) \in \mathrm{R},(\eta-\lambda)>-1 / 2,|\arg \mathrm{z}|<\pi / 2$.

\section{Teknik Transformasi Variabel}

Misalkan $X$ variabel acak kontinu yang memiliki p.d.f $\mathrm{f}(\mathrm{x})$ dimana $\mathrm{f}(\mathrm{x})>0$ untuk $\mathrm{x} \in \mathrm{A}$ dimana $\mathrm{A}=$ $\{\mathrm{x} \mid \mathrm{x} \in \mathrm{R}\}$ dan $\mathrm{Y}=\mathrm{u}(\mathrm{X})$ adalah fungsi dari variabel acak kontinu $\mathrm{X}$ dimana $\mathrm{y}=\mathrm{u}(\mathrm{x})$ mendefinisikan transformasi satu-satu yang memetakan $\mathrm{B}$ ke $\mathrm{B}$ dimana $\mathrm{B}=\{\mathrm{y} \mid \mathrm{y} \in \mathrm{R}\}$. Karena $\mathrm{y}=\mathrm{u}(\mathrm{x})$ merupakan transformasi satu-satu maka $\mathrm{y}=\mathrm{u}(\mathrm{x})$ memiliki invers yang memetakan $\mathrm{B}$ ke $\mathrm{A}$, dinotasikan $\mathrm{x}=\mathrm{w}(\mathrm{y})$. Jika $\mathrm{dx} / \mathrm{dy}=\mathrm{w}^{\prime}(\mathrm{y})$ kontinu di setiap $\mathrm{y} \in \mathrm{B}$ p.d.f dari $\mathrm{Y}=\mathrm{u}(\mathrm{X})$ adalah

$$
\mathrm{g}(\mathrm{y})=\mathrm{f}(\mathrm{w}(\mathrm{y}))\left|\mathrm{w}^{\prime}(\mathrm{y})\right|, \mathrm{y} \in \mathrm{B}
$$

Misalkan $X_{1}$ dan $X_{2}$ variabel acak kontinu yang memiliki p.d.f bersama $f\left(x_{1}, x_{2}\right)$ dimana $f\left(x_{1}, x_{2}\right)>0$ untuk $\mathrm{x}_{1}$ dan $\mathrm{x}_{2}$ element $\mathrm{A}$ dimana $\mathrm{A}=\left\{\left(\mathrm{x}_{1}, \mathrm{X}_{2}\right) \mid \mathrm{x}_{1} \in \mathrm{R}, \mathrm{x}_{2} \in \mathrm{R}\right\}$. Misalkan variabel acak $\mathrm{Y}_{1}$ dan $\mathrm{Y}_{2}$ yang merupakan fungsi dari $\mathrm{X}_{1}$ dan $\mathrm{X}_{2}$ ditulis $\mathrm{Y}_{1}=\mathrm{u}_{1}\left(\mathrm{X}_{1}, \mathrm{X}_{2}\right)$ dan $\mathrm{Y}_{2}=\mathrm{u}_{2}\left(\mathrm{X}_{1}, \mathrm{X}_{2}\right)$. Sehingga $\mathrm{y}_{1}=$ $\mathrm{u}_{1}\left(\mathrm{x}_{1}, \mathrm{x}_{2}\right)$ dan $\mathrm{y}_{2}=\mathrm{u}_{2}\left(\mathrm{x}_{1}, \mathrm{x}_{2}\right)$ transformasi satu ke satu yang memetakan $\mathrm{A}$ ke $\mathrm{B}$, dimana $\mathrm{B}=\left\{\left(\mathrm{y}_{1}, \mathrm{y}_{2}\right) \mid \mathrm{y}_{1}\right.$ $\left.\in R, y_{2} \in R\right\}$. Transformasi satu ke satu dari fungsi $Y_{1}$ dan $Y_{2}$ yang memetakan $A$ ke $B$ dari $y_{1}=$ $\mathrm{u}_{1}\left(\mathrm{x}_{1}, \mathrm{x}_{2}\right)$ dan $\mathrm{y}_{2}=\mathrm{u}_{2}\left(\mathrm{x}_{1}, \mathrm{x}_{2}\right)$ mempunyai invers yang memetakan $\mathrm{B}$ ke $\mathrm{A}$ yakni $\mathrm{x}_{1}=\mathrm{w}_{1}\left(\mathrm{y}_{1}, \mathrm{y}_{2}\right)$ dan $\mathrm{x}_{3}=$ $\mathrm{w}_{2}\left(\mathrm{y}_{1}, \mathrm{y}_{2}\right)$. Misalkan $\mathrm{Y}_{1}$ dan $\mathrm{Y}_{2}$ fungsi dari $\mathrm{X}_{1}$ dan $\mathrm{X}_{2}$ ditulis $\mathrm{Y}_{1}=\mathrm{u}_{1}\left(\mathrm{x}_{1}, \mathrm{X}_{2}\right)$ dan $\mathrm{Y}_{2}=\mathrm{u}_{2}\left(\mathrm{x}_{1}, \mathrm{X}_{2}\right)$ maka p.d.f bersama dari $Y_{1}$ dan $Y_{2}$ adalah dimana

$$
\mathrm{g}\left(\mathrm{y}_{1}, \mathrm{y}_{2}\right)=\mathrm{f}\left(\mathrm{w}_{1}\left(\mathrm{y}_{1}, \mathrm{y}_{2}\right), \mathrm{w}_{2}\left(\mathrm{y}_{1}, \mathrm{y}_{2}\right)\right)|\mathrm{J}|
$$


$|\mathbf{J}|=\left|\begin{array}{ll}\frac{\partial x_{1}}{\partial y_{1}} & \frac{\partial x_{1}}{\partial y_{2}} \\ \frac{\partial x_{2}}{\partial y_{1}} & \frac{\partial x_{2}}{\partial y_{2}}\end{array}\right|$

\section{Fungsi Gamma}

Misalkan $\mathrm{a}>0$, maka fungsi Gamma

$$
\Gamma(\mathrm{a})=\int_{0}^{\infty} y^{\mathrm{a}-1} e^{-y} \text {, untuk } \mathrm{y}>0
$$

Grafik dari fungsi Gamma yang diintegralkan untu $\alpha=1, \alpha=2, \alpha=3, \alpha=4$ terlihat pada Gambar 2.1

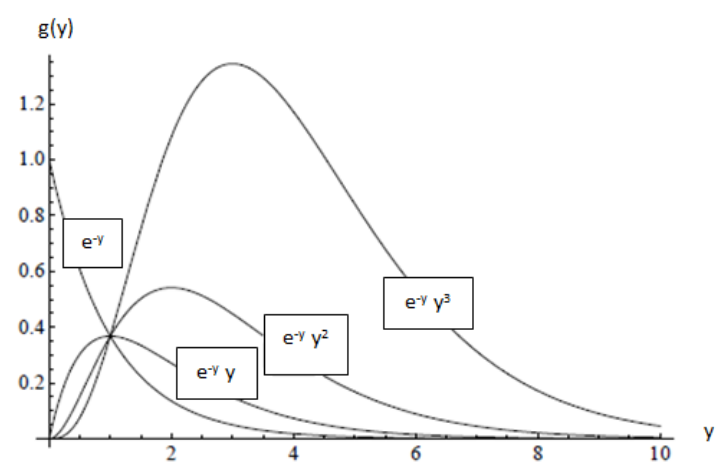

\section{GAMBAR 2.1 KURVA INTEGRAL DARI FUNGSI GAMMA}

Kurva ini secara perlahan berubah bentuk sesuai dengan nilai parameter, semakin besar nilai parameter maka bentuk kurva semakin runcing.

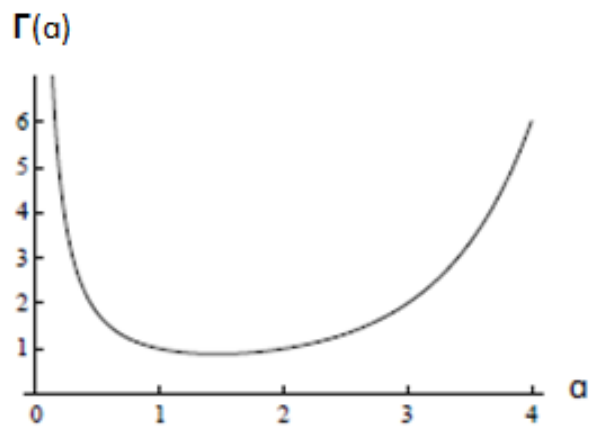

\section{GAMBAR 2.2 GRAFIK HASIL NILAI DARI I(A) $€ \mathrm{Z}^{+}$}

Gambar 2.2 merupakan hasil fungsi Gamma $\Gamma(\alpha)=(\alpha-1)$ ! dimana $\alpha$ merupakan bilangan bulat positif. Ketika $\alpha=1$ maka $\Gamma(1)=1, \alpha=2 \operatorname{maka} \Gamma(2)=1, \alpha=3$ maka $\Gamma(3)=2.5, \alpha=4$ maka $\Gamma(4)=6$ dan seterusnya.

\section{Fungsi Beta}

Fungsi Beta didefinisikan sebagai

$$
\mathrm{B}(\mathrm{y}, \mathrm{z})=\int_{0}^{1} t^{y-1}(1-t)^{z-1} \mathrm{dt}
$$

untuk $y, z \in R, y>0, z>0$ dan $t \in R, 0 \leq t \leq 1$.

\section{Distribusi Gamma}

Fungsi kepadatan peluang variabel acak X berdistribusi Gamma dengan parameter $a>0$ dan $\theta=\frac{1}{\beta}$ adalah

$$
\mathrm{p}(\mathrm{x})=\beta^{\alpha} \mathrm{x}^{\alpha-1} \mathrm{e}^{-\beta \mathrm{x}} / \Gamma(\mathrm{a}) \text { untuk } 0<\mathrm{x}<\infty
$$




\section{Distribusi Beta}

Fungsi kepadatan peluang variabel acak Y berdistribusi Beta dengan parameter a dan $\beta$ adalah $\mathrm{g}(\mathrm{y})=\frac{y^{a-1}(1-y)^{\beta-1}}{\Gamma(a) \Gamma(\beta)} \Gamma(\mathrm{a}+\beta)$, untuk $0<\mathrm{y}<1$

\section{HASIL DAN PEMBAHASAN}

\section{Konstruksi Distribusi Gamma Bivariat}

Lemma 3.1. Misalkan terdapat variabel acak $\mathrm{U}$ dan $\mathrm{V}$ yang saling independen, kontinu, dan bernilai nonnegatif. Maka untuk sebarang $\mathrm{a}>0$ dan $\mathrm{b}>0$, sebarang dua dari pernyataan berikut mengakibatkan tiga kondisi sebagai berikut:

(i) U berdistribusi Beta dengan parameter (a,b) .

(ii) $\mathrm{V}$ berdistribusi Gamma dengan parameter $(\mathrm{a}+\mathrm{b}, 1 / \mu)$.

(iii) UV berdistribusi Gamma dengan parameter (a, $1 / \mu)$ dimana $0<\mu<\infty$.

(Nadrajah, 2006).

Misalkan terdapat dua variabel berdistribusi Gamma dan satu variabel berdistribusi Beta. Asumsikan dua variabel $\mathrm{U} \sim \operatorname{Gamma}\left(\mathrm{c}, 1 / \mu_{1}\right)$ dan $\mathrm{V} \sim \operatorname{Gamma}\left(\mathrm{c}, 1 / \mu_{2}\right)$ dan satu variabel $\mathrm{W} \sim \operatorname{Beta}(\mathrm{a}, \mathrm{b})$ dimana c=a+b. Definisikan

dengan menggunakan pdf fungsi Gamma

$$
\mathrm{X}=\mathrm{UW} \text { dan } \mathrm{Y}=\mathrm{VW}
$$

$$
p(t)=\beta^{\alpha} t^{\alpha-1} e^{-\beta t} / \Gamma(a) \text { untuk } 0<t<\infty
$$

Gunakan fungsi Whittaker untuk menunjukkan pdf bersama dari distribusi Gamma bivariat.

$$
\mathrm{W}_{\lambda, \eta}(\mathrm{z})=\mathrm{z}^{\eta+1 / 2} \exp (-\mathrm{z} / 2) / \Gamma(\eta-\lambda+1 / 2) \int_{0}^{\infty} \exp (-z t) t^{\eta-\lambda-1 / 2}(1+t)^{\eta+\lambda-1 / 2} d t
$$

Pdf bersama distribusi Gamma bivariat

$$
\mathrm{g}(\mathrm{x}, \mathrm{y})=\mathrm{kr}(\mathrm{b})(\mathrm{xy})^{\mathrm{c}-1}\left(\frac{x}{\mu_{1}}+\frac{y}{\mu_{2}}\right)^{\frac{\alpha-1}{2}-\mathrm{c}} \exp \left\{-\frac{1}{2}\left(\frac{x}{\mu_{1}}+\frac{y}{\mu_{2}}\right)\right\} W_{c-b+\frac{1-\alpha}{2}, c-\frac{\alpha}{2}}\left(\frac{x}{\mu_{1}}+\frac{y}{\mu_{2}}\right)
$$

untuk $\mu_{1}>0, \mu_{2}>0, \alpha>0, \mathrm{~b}>0, \mathrm{x}>0$, dan $\mathrm{y}>0$, dan $\mathrm{k}$ adalah

Pdf bersama dari $\mathrm{U}, \mathrm{V}$ dan $\mathrm{W}$ adalah

$$
\mathrm{k}=\frac{1}{\left(\mu_{1} \mu_{2}\right)^{c} \mathrm{r}(a) \Gamma(b) \Gamma(c)}
$$

$$
\mathrm{f}(\mathrm{u}, \mathrm{v}, \mathrm{w})=\mathrm{k}(\mathrm{uv})^{\mathrm{c}-1} \mathrm{w}^{\alpha-1}(1-\mathrm{w})^{\mathrm{b}-1} \exp \left\{-\left(\frac{u}{\mu_{1}}+\frac{v}{\mu_{2}}\right)\right\}
$$

maka pdf bersama dari $\mathrm{X}, \mathrm{Y}$ dan $\mathrm{W}$ menjadi

$$
\mathrm{f}(\mathrm{x}, \mathrm{y}, \mathrm{w})=\mathrm{k}(\mathrm{xy})^{\mathrm{c}-1} \mathrm{w}^{\alpha-2 \mathrm{c}-1}(1-\mathrm{w})^{\mathrm{b}-1} \exp \left\{-\frac{1}{w}\left(\frac{x}{\mu_{1}}+\frac{y}{\mu_{2}}\right)\right\}
$$

Integralkan $\mathrm{f}(\mathrm{x}, \mathrm{y}, \mathrm{w})$ terhadap w sehingga,

$$
f(x, y)=k(x y)^{c-1} I(x, y)
$$

dimana $\mathrm{I}(\mathrm{x}, \mathrm{y})$ adalah

$$
\mathrm{I}(\mathrm{x}, \mathrm{y})=\int_{0}^{1} \mathrm{w}^{\alpha-2 \mathrm{c}-1}(1-\mathrm{w})^{\mathrm{b}-1} \exp \left\{-\frac{1}{w}\left(\frac{x}{\mu_{1}}+\frac{y}{\mu_{2}}\right)\right\} \mathrm{dw}
$$

Substitusi $\mathrm{u}=1 / \mathrm{w}-1$ dan menggunakan fungsi Whittaker, sehingga

$$
\mathrm{I}(\mathrm{x}, \mathrm{y})=\Gamma(\mathrm{b})\left(\frac{x}{\mu_{1}}+\frac{y}{\mu_{2}}\right)^{\frac{\alpha-1}{2}-\mathrm{c}} \exp \left\{-\frac{1}{2}\left(\frac{x}{\mu_{1}}+\frac{y}{\mu_{2}}\right)\right\} W_{c-b+\frac{1-\alpha}{2}, c-\frac{\alpha}{2}}\left(\frac{x}{\mu_{1}}+\frac{y}{\mu_{2}}\right)
$$

\section{P.d.f Bersyarat Distribusi Gamma Bivariat}

Setelah mendapatkan fungsi p.d.f bersama distribusi Gamma bivariat, selanjutnya mencari p.d.f bersyarat dari distribusi Gamma bivariat. Untuk mencari p.d.f bersyarat dari distribusi Gamma bivariat diperlukan juga p.d.f dari $\mathrm{X}$ dan $\mathrm{Y}$.

Fungsi p.d.f dari $\mathrm{X}$ adalah 


$$
\mathrm{f}(\mathrm{x})=\frac{1}{\mu_{1}^{a} \Gamma(a)} x^{a-1} \exp \left(-\frac{x}{\mu_{1}}\right)
$$

Fungsi p.d.f dari $\mathrm{Y}$ adalah

$$
\mathrm{g}(\mathrm{y})=\frac{1}{\mu_{2}^{a} \Gamma(a)} y^{a-1} \exp \left(-\frac{y}{\mu_{2}}\right)
$$

untuk $\mu_{1}>0, \mu_{2}>0, \alpha>0, \mathrm{x}>0$, dan $\mathrm{y}>0$.

Fungsi p.d.f bersyarat dari $\mathrm{X}$ bersyarat $\mathrm{Y}$ adalah

$$
\mathrm{g}(\mathrm{x} \mid \mathrm{y})=\mathrm{kx}^{\mathrm{c}-1} \mathrm{y}^{\mathrm{b},} \mu_{1}^{\alpha} \Gamma(a) \Gamma(b)\left(\frac{x}{\mu_{1}}+\frac{y}{\mu_{2}}\right)^{\frac{\alpha-1}{2}-\mathrm{c}} \exp \left\{\frac{1}{2}\left(-\frac{x}{\mu_{1}}+\frac{y}{\mu_{2}}\right)\right\} W_{c-b+\frac{1-\alpha}{2}, c-\frac{\alpha}{2}}\left(\frac{x}{\mu_{1}}+\frac{y}{\mu_{2}}\right)
$$

Fungsi p.d.f bersyarat dari $\mathrm{Y}$ bersyarat $\mathrm{X}$ adalah

$$
\mathrm{g}(\mathrm{y} \mid \mathrm{x})=\mathrm{kx}^{\mathrm{b}} \mathrm{y}^{\mathrm{c}-1,} \mu_{1}^{\alpha} \Gamma(a) \Gamma(b)\left(\frac{x}{\mu_{1}}+\frac{y}{\mu_{2}}\right)^{\frac{\alpha-1}{2}-\mathrm{c}} \exp \left\{\frac{1}{2}\left(-\frac{x}{\mu_{1}}+\frac{y}{\mu_{2}}\right)\right\} W_{c-b+\frac{1-\alpha}{2}, c-\frac{\alpha}{2}}\left(\frac{x}{\mu_{1}}+\frac{y}{\mu_{2}}\right)
$$

\section{Karakteristik Distribusi Gamma Bivariat}

Berdasarkan Lemma 3.1 distribusi Gamma bivariat akan berkorelasi, sehingga akan dikonstruksi karakteristik dari distribusi Gamma bivariat. Karakteristik yang dimaksud adalah product moment, kovariansi, dan korelasi dari distribusi Gamma bivariat.

Product Moment dari X dan Y adalah

$$
\mathrm{E}\left(\mathrm{X}^{\mathrm{m}} \mathrm{Y}^{\mathrm{n}}\right)=\frac{\mu_{1}^{m} \mu_{2}^{n} \Gamma(m+c) \Gamma(n+c) B(m+n+a, b)}{\Gamma(a) \Gamma(b) \Gamma(c)}
$$

Kovariansi dari $\mathrm{X}$ dan $\mathrm{Y}$ adalah

$$
\operatorname{Cov}(X, Y)=\frac{\mu_{1} \mu_{2} a b}{a+b+1}
$$

Korelasi dari $\mathrm{X}$ dan $\mathrm{Y}$ adalah

$$
\operatorname{Corr}(X, Y)=\frac{b}{a+b+1}
$$

\section{KESIMPULAN DAN SARAN}

\section{Kesimpulan}

Pada skripsi ini telah dibahas mengenai konstruksi dan karakteristik dari distribusi Gamma bivariat. Karakteristik yang dimaksud yakni, product moment, kovariansi, dan korelasi. Distribusi Gamma bivariat dapat dikonstruksi oleh distribusi Gamma dan distribusi Beta dengan mengasumsikan bahwa $\mathrm{X}=\mathrm{UW}$ dan $\mathrm{Y}=\mathrm{VW}$, dimana $\mathrm{U} \sim \operatorname{Gamma}\left(\mathrm{c}, 1 / \mu_{1}\right), \mathrm{V} \sim \operatorname{Gamma}\left(\mathrm{c}, 1 / \mu_{2}\right)$ dan $\mathrm{W} \sim \operatorname{Beta}(\mathrm{a}, \mathrm{b}) \operatorname{dengan} \mathrm{c}=$ $\mathrm{a}+\mathrm{b}$

1. Fungsi p.d.f bersama distribusi Gamma bivariat adalah

$$
\mathrm{g}(\mathrm{x}, \mathrm{y})=\mathrm{k} \Gamma(\mathrm{b})(\mathrm{xy})^{\mathrm{c}-1}\left(\frac{x}{\mu_{1}}+\frac{y}{\mu_{2}}\right)^{\frac{\alpha-1}{2}-\mathrm{c}} \exp \left\{-\frac{1}{2}\left(\frac{x}{\mu_{1}}+\frac{y}{\mu_{2}}\right)\right\} W_{c-b+\frac{1-\alpha}{2}, c-\frac{\alpha}{2}}\left(\frac{x}{\mu_{1}}+\frac{y}{\mu_{2}}\right)
$$

2. Karakteristik dari distribusi Gamma bivariat adalah

\section{Product moment}

$$
\mathrm{E}\left(\mathrm{X}^{\mathrm{m}} \mathrm{Y}^{\mathrm{n}}\right)=\frac{\mu_{1}^{m} \mu_{2}^{n} \Gamma(m+c) \Gamma(n+c) B(m+n+a, b)}{\Gamma(a) \Gamma(b) \Gamma(c)}
$$

Kovariansi

$$
\operatorname{Cov}(X, Y)=\frac{\mu_{1} \mu_{2} a b}{a+b+1}
$$

Korelasi

$$
\operatorname{Corr}(X, Y)=\frac{b}{a+b+1}
$$

\section{Saran}

Saran dari penulis yaitu, dapat dilanjutkan dengan mengkonstruksi bentuk-bentuk distribusi Gamma bivariat yang lain seperti contoh Jensen's Gamma Bivariat. 


\section{UCAPAN TERIMA KASIH}

Terima kasih kepada dosen pembimbing dan seluruh pihak yang telah memberikan bantuan kepada penulis dalam menyelesaikan penelitian ini.

\section{REFERENSI}

Bain, Lee J., Engelhardt, Max. 1991. Introduction to Probability and Mathematical Statistics. 2nd Edition. California: Duxbury Press.

Bonnar. (2017), The Gamma Function. United States, hh. 1-163.

Gradshteyn, I.S. \& Ryzhik, I.M. (2007). Table of Integrals, Series, and Products. 7th Edition. USA: Academic Press.

Hogg, Robert V. \& Craig, Allen T. (1995). Introduction to Mathematical Statistics. 4th Edition. New Jersey: Prentice-Hall International, Inc.

Kim, B., \& Kim, J. (2017). The Maximum Distribution of Kibble's Bivariate Gamma Random Vector. Operations Research Letters, 45, hh. 392-396.

Markovic, R. D. (1965). Probablity Functions of Best Fit to Distributions of Annual Precipitation and Runoff. Colo. St. Univ., Fort Collins, Hydrol.

Nadarajah, Saralees \& Gupta, Arjun K. (2006). Some Bivariate Gamma Distributions. Applied Mathematics Letters, 19, hh. 767-774.

Nadarajah, Saralees \& Gupta, Arjun K. (2006). Intensity-Duration Models Based on Bivariate Gamma Distributions. Hiroshima Math. J, hh. 387-395. 